\title{
THE ALTERATION OF SAGITTAL LUMBOSACRALALIGNMENT AFTER POSTERIOR STABILIZATION-FUSION IN LUMBAR SPONDYLOLISTHESIS: CLINICAL STUDY
}

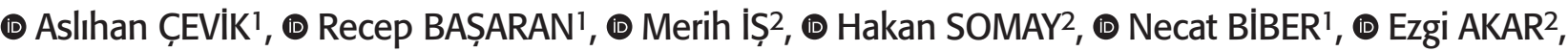 \\ (1) Mehmet Zafer BERKMAN² \\ 1 Medical Sciences University, Sancaktepe Training and Research Hospital, Clinic of Neurosurgery, Istanbul, Turkey \\ ${ }_{2}^{2}$ Medical Sciences University, Haydarpaşa Numune Training and Research Hospital, Clinic of Neurosurgery, İstanbul, Turkey
}

\begin{abstract}
Objective: Spondylolisthesis (SL) is a condition that occurs in $2-8 \%$ of the general population. Sagittal spinopelvic alignment determines the mechanical stress in the lumbosacral junction. The aim of this study is to understand how much we can correct sagittal lumbosacral alignment to maintain sagittal balance in SL by surgical treatment and to demonstrate the effectiveness of posterior fixation in maintaining sagittal balance. Materials and Methods: We retrospectively reviewed the cases operated with SL between January 2011 and June 2016. Wiltse classification was used to determine the type of SL. The parameters of sagittal balance (slip rate, slip angle, lumbar lordosis angle, lumbosacral kyphosis and sacral slope) were evaluated preoperatively and postoperatively.

Results: The study was carried out with 63 cases, 31.7\% $(n=20)$ male and $68.3 \%(n=43)$ female. The mean age was $57.16 \pm 12.55$ years. The correction of slip rate and slip angle was found to be statistically significant $(p<0.01)$.

Conclusion: The objective of our study was to investigate how the surgery influenced sagittal spino-pelvic alignment of SL and to investigate the correlation between the effectiveness and the changes of spine-pelvic sagittal parameters for patients with SL before and after operation. Keywords: Spondylolisthesis, sagittal, balance, lumbosacral, alignment, surgery
\end{abstract}

\section{INTRODUCTION}

Spondylolisthesis (SL) is the subluxation of a vertebral body over another vertebral body in sagittal plane. SL occurs in $2-8 \%$ of the general population and affects all age groups. The common mechanism of this intervertebral instability is ligamentous weakness and laxity, pars interarticularis defect, previous surgical intervention or trauma ${ }^{(1,2)}$.

The clinical stability of the spine is the ability of the spine to limit the translocation pattern when physiological load is

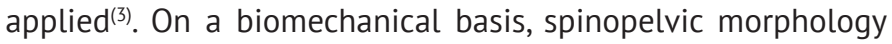
plays a critical role in determining the direction and magnitude of forces acting across the lumbosacral junction ${ }^{(4)}$. Normal sagittal alignment of the spine and pelvis would be helpful to maintain a stable posture and to expend a minimum of energy. $\mathrm{SL}$, with the abnormal sacropelvic morphology, may disturb the normal spino-pelvic sagittal balance and result in the abnormal sacro-pelvic orientation. In SL, the instability is that the spinal column cannot limit excessive and abnormal translations ${ }^{(3)}$. The instability in lumbar SL usually progresses slowly. SL sometimes has progressive deformity ${ }^{(5)}$.

Various classifications were made about the cause of SL. The universally accepted classification was proposed by Wiltse et al. ${ }^{(6)}$. The grading of SL was done by Myerding ${ }^{(7)}$.

The major surgical indications are neurogenic claudication, persistent radiculopathy, severe back pain, presence of neurological symptoms, conservative treatment failure, radiological instability, progression of listhesis, Myerding grade (Gr) III and Gr IV listhesis, and spondyloptosis $(\mathrm{Gr} \mathrm{V})^{(7,8)}$.

Sagittal sacropelvic morphology and orientation determine the lumbar spine geometry as the mechanical stress in the lumbosacral junction. For better understanding of the development of SL, several parameters have been described to define the relationship between the lumbosacral junction and the pelvis ${ }^{(9,10)}$. These parameters include pelvic inclination (PI), pelvic tilt, lumbar lordosis (LL), and sacral slope (SS).

The objective of our study was to investigate how the surgery influenced sagittal spino-pelvic alignment of SL and to investigate the correlation between the effectiveness and 
the changes of spine-pelvic sagittal parameters for patients with SL before and after operation.

\section{MATERIAL AND METHODS}

We retrospectively reviewed the cases operated for lumbosacral SL between January 2011 and June 2016. The age, gender, level of listhesis, type and grade of SL were recorded. Wiltse classification was used to determine the type of SL ${ }^{(6)}$. Myerding classification was used to determine the percentage of slip that one vertebral body had slipped forward over the vertebral body below in $\mathrm{SL}^{(7)}$. Direct lumbosacral anteroposterior, lateral, flexion-extension functional radiographies, computerized tomography and magnetic resonance imaging examinations were evaluated before and after surgery. Pedicle screw fixation and posterolateral fusion were applied to all patients by the

Table 1. Demographic features of the cases

\begin{tabular}{|c|c|c|c|}
\hline \multicolumn{2}{|l|}{ 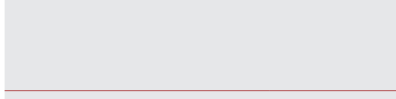 } & $\begin{array}{l}\text { Min-Max } \\
\text { (median) }\end{array}$ & Mean \pm SD \\
\hline \multicolumn{2}{|l|}{ Age (years) } & $15-76(60)$ & $57.16 \pm 12.55$ \\
\hline \multirow{2}{*}{\multicolumn{2}{|c|}{ Follow-up (months) }} & $\begin{array}{l}10 \text { days }-53 \\
\text { months }\end{array}$ & $9.81 \pm 11.58$ \\
\hline & & $\mathrm{n}$ & $\%$ \\
\hline \multirow{2}{*}{ Gender } & Male & 20 & 31.7 \\
\hline & Female & 43 & 68.3 \\
\hline \multirow{3}{*}{$\begin{array}{l}\text { Meyerding } \\
\text { classification }\end{array}$} & Grade 1 & 23 & 36.5 \\
\hline & Grade 2 & 39 & 61.9 \\
\hline & Grade 3 & 1 & 1.6 \\
\hline
\end{tabular}

SD: Standard deviation, min: Minimum, max: Maximum, n: Sayı same surgeon. The surgical procedure was pedicle screw fixation and posterolateral fusion. Myerding slip rate (SR), slip angle (SA), LL angle, lumbosacral kyphosis (LSK), and SS measurements were performed and compared to investigate morphologic changes after surgery.

\section{Statistical Analysis}

NCSS (Number Cruncher Statistical System) 2007 (Kaysville, Utah, USA) program was used for statistical analysis. Descriptive statistical methods (mean, standard deviation, median, frequency, Odds ratio, minimum, and maximum) were used while evaluating the study data. Paired sample t-test was used for intra-group comparison of normally distributed parameters and Wilcoxon Signed Ranks test was used for intragroup comparison of non-normally distributed parameters. Significance was evaluated at $p<0.05$ level.

\section{RESULTS}

The study was carried out with 63 cases, $31.7 \%(n=20)$ male and $68.3 \%(n=43)$ female. The ages of the cases ranged from 15 to 76 years with a mean of $57.16 \pm 12.55$ years. The followup period ranged from 3 to 53 months and the mean followup was $12.81 \pm 11.58$ months (Table 1 ). According to Wiltse classification, the degenerative type was $55.6 \%(n=35)$, the isthmic type was $41.3 \%(n=26)$, the dysplastic type was $1.6 \%$ $(n=1)$ and the iatrogenic type was $1.6 \%(n=1)$ SL. Retrolisthesis ratio was $11.1 \%(n=7)$. We found that $L 1-2$ level was $1.6 \%(n=1)$, L2-3 level was 3.2\% ( $n=2)$, L3-4 level was 16\% ( $n=10)$, and L4-5 level was $50.7 \%(n=32)$ and $28.5 \%$ of the L5-S1 level $(n=18)$. Preoperatively, considering Myerding grades SR, Gr I was found in $36.5 \%$ ( $n=23), G R$ II was found in $61.9 \%(n=39)$ and Gr III in

Table 2. Statistical results of slip rate, slip angle, lumbar lordosis, lumbosacral kyphosis and sacral slope

\begin{tabular}{|c|c|c|c|c|}
\hline & & Min-Max (Median) & Mean \pm SD & $\mathbf{p}$ \\
\hline \multirow{3}{*}{ Slope rate (\%) } & Preop & $17-55(26.2)$ & $27.96 \pm 7.31$ & \multirow{3}{*}{0.001} \\
\hline & Postop & $0-49(16.9)$ & $16.52 \pm 9.72$ & \\
\hline & Difference & $-11.44 \pm 5.88$ & & \\
\hline Slope angle $\left(^{\circ}\right)$ & Preop & $-2.2-30.4(9.8)$ & $-10.62 \pm 5.95$ & 0.001 \\
\hline \multirow{3}{*}{ Lumbar lordosis $\left({ }^{\circ}\right)$} & Preop & $34-71.9(52.1)$ & $52.14 \pm 8.43$ & \multirow{3}{*}{0.159} \\
\hline & Postop & $37.2-68.8(49.4)$ & $50.96 \pm 6.97$ & \\
\hline & Difference & $-1.18 \pm 6.59$ & & \\
\hline Lumbosacral kyphosis $\left({ }^{\circ}\right)$ & Preop & $11.7-52.7^{\circ}(30.4)$ & $30.27 \pm 10.09$ & 0.253 \\
\hline \multirow[t]{2}{*}{ Sacral slope $\left(^{\circ}\right)$} & Postop & $16.2-53.8(35.1)$ & $35.60 \pm 7.36$ & \multirow[t]{2}{*}{0.036} \\
\hline & Difference & $-1.26 \pm 4.64$ & & \\
\hline
\end{tabular}

SD: Standard deviation, min: Minimum, max: Maximum, preop: Preoperative, postop: Postoperartive Wilcoxon Signed Rank Test 
$1.6 \%(n=1)$. For postoperatively Myerding grades, $90.5 \%$ of the cases ( $n=57)$ were $\mathrm{Gr} I$ and $9.5 \%(n=6)$ were $\mathrm{Gr}$ II. Postoperative SR was found to be statistically significant, as low as $11.44 \pm 5.88$ $(p=0.001 ; p<0.01)$ (Table 2).

The preoperative SA ranged from $-2.2^{0}$ to $-30.4^{0}$, with a mean of $-10.62 \pm 5.95$ and a postoperative SA ranged from 0 to 25 , with an average of $-6.96 \pm 4.59$. Postoperative SA was significantly lower than preoperative SA, 3.66 $\pm 2.99(p=0.001 ; p<0.01)$ (Table 2).

There was no statistically significant difference between the preoperative and postoperative LL measurements $(p=0.159$; $\mathrm{p}>0.05$ ) (Table 2).

Preoperative LSK ranged from 11.7 to $52.7^{\circ}$ with a mean of 30.27 \pm 10.090 ; postoperative LSK was between 14.3 and 47.90, with an average of $29.79 \pm 8.750$. The change of LSK was not statistically significant $(p>0.05)$ (Table 2$)$.

Postoperative SS was found to be statistically significant, as low as $1.26 \pm 54.64(p=0.036 ; p<0.05)$ (Table 2$)$.

\section{DISCUSSION}

The flexion, extension, rotation and lateral bending movements performed at different levels of the spine must be done within certain intervals for a person to maintain his/her daily life activities. Pathologies that occur in the spine restrict this range of motion or cause non-physiological movements to occur. SL involves the subluxation of a vertebral body over another vertebral body in the sagittal plane ${ }^{(1,2)}$. The aim of spinal surgery is to make these pathological processes as physiological as possible.

The most common type of $S L$ is degenerative type and it is followed by the isthmic type. Kalichman et al.(1) found degenerative type to be at the rate of $65.7 \%$ and isthmic type SL to be at the rate of $39.6 \%$ in their study. In our study, the most common type was degenerative and it is followed by isthmic SL as in literature. SL is more common in women ${ }^{(11)}$. The most common level is $L 4-L 5^{(12)}$. Retrolisthesis is most commonly found in the L3-L4 level, which is a rare condition ${ }^{(11)}$. According to Labelle, the most important measures in evaluating SL are grade, LL, LSK, SS and SA ${ }^{(9)}$.

The degree of the listhesis is based on the percentage of slip according to Myerding Classification ${ }^{(7)}$. In the literature, there is no study comparing preoperative and postoperative shifts. Our study revealed that when all the cases are evaluated, the average shift is about $11 \%$. This suggests that the degree of listhesis can be corrected by surgery.

It is the intersection of the lower endplate of the upper vertebrae and the vertebrae passing through the upper endplate of the underlying vertebra ${ }^{(13)}$. Huang and colleagues found that the preoperative SA was $-20.3 \pm 2.8^{0}$ in $\mathrm{HGS}$ and $-8.5 \pm 5.4^{0}$ in $\mathrm{LGS}\left({ }^{(4)}\right.$.

When we investigated the change in preoperative and postoperative SA in our study, it was seen that the change was $-10.62^{\circ}$ on average. It was found that the most prominent correction of SA was achieved with surgery.
LL and LSK are evaluated by lateral lumbosacral radiography. There are many factors affecting LL, such as age, gender, body mass index, and race, which make it difficult to obtain mean values. There is a strong correlation between $\mathrm{LL}$ and SL. In some studies, performed in the literature, the mean $L L$ values range from 50.36 to $56.5^{(14,15)}$.

In our study, preoperative LL angle was $52.14 \pm 8.43$ and postoperative $\mathrm{LL}$ angle was $50.96 \pm 6.97$. The $\mathrm{LL}$ angle was reduced by about $2^{0}$ in the postoperative period. It is seen that there is no significant improvement in the LL surgically.

The physical findings of the listhesis are related to the degree of slip and $\mathrm{LSK}^{(16)}$. There is no valid consensus to assess the LSK. Boxall SA, Dubousset LSA, SDSG LSA, Dysplastic SDSG LSA, Sagittal Rotation and Kyphotic Cobb angle can be used.

In our study, the change in preoperative and postoperative LSK angle was found to be less than an increase of grade. It is not possible to correct this angle by applying surgery.

$\mathrm{S} 1$ is the angle between the upper endplate and the horizontal line. Normal PI and SS values range from $42 \pm 5$ to $74 \pm 1^{\circ}$ and $35 \pm 4$ to $53 \pm 7^{(10,17)}$. Along with the development of listhesis, these values are increasing ${ }^{(18)}$.

In our study, the SS mean value increased by about $1.26^{\circ}$. This significant result suggests that it is possible to surgically correct the sacral SA.

\section{CONCLUSION}

SL occurs in the sagittal plane with subluxation of a vertebrae body through another vertebral body. Sagittal sacropelvic morphology and orientation determine the lumbar spine geometry as the mechanical stress in the lumbosacral junction. Lumbosacral malalignment in this region affects the development and progression of SL. It is possible to approximate the amount of SR, SA and SS to normal ranges by the surgery but this not possible for the LL and LSK.

\section{Ethics}

Ethics Committee Approval: Retrospective study. Informed Consent: Retrospective study.

\section{Authorship Contributions}

Surgical and Medical Practices: A.Ç., R.B., M.I.., H.S., N.B., E.A., M.Z.B., Concept: A.Ç., M.I.., M.Z.B., Design: A.Ç., M.I., M.Z.B., R.B., Data Collection or Processing: A.Ç., Analysis or Interpretation: A.Ç., R.B., Literature Search: A.Ç., R.B., Writing: A.Ç., R.B.

Conflict of Interest: No conflict of interest was declared by the authors.

Financial Disclosure: The authors declared that this study received no financial support.

\section{REFERENCES}

1. Kalichman L, Kim DH, Li L, Guermazi A, Berkin V, Hunter DJ Spondylolysis and spondylolisthesis: prevalence and association with low back pain in the adult community-based population. Spine (Phila 
Pa 1976). 2009;34:199-205.

2. Simotas AC, Dorey FJ, Hansraj KK, Cammisa F Jr. Nonoperative treatment for lumbar spinal stenosis: clinical and outcome results and a 3-year survivorship analysis. Spine (Phila Pa 1976). 2000;25:197-203.

3. White AA, Panjabi MM (Eds). Clinical biomechanics of the spine. Vol. 2. 1990: Lippincott, Philadelphia 1990;pp:2.

4. Huang RP, Bohlman HH, Thompson GH, Poe-Kochert C. Predictive value of pelvic incidence in progression of spondylolisthesis. Spine (Phila Pa 1976). 2003;28:2381-5.

5. Benzel EC. Biomechanics of spine stabilization. 3rd edition. Thieme.2015.

6. Wiltse LL, Newman PH, Macnab I. Classification of Spondyloisis and Spondylolisthesis. Clin Orthop Relat Res. 1976;117:23-9.

7. Myerding H. Spondylolisthesis. Surg Gynecol Obstet. 1932;54:371-7.

8. Eismont FJ, Norton RP, Hirsch BP. Surgical management of lumbar degenerative spondylolisthesis. I Am Acad Orthop Surg. 2014;22:203-13.

9. Labelle H, Roussouly P, Berthonnaud E, Dimnet J, O'Brien M. The importance of spino-pelvic balance in L5-s1 developmental spondylolisthesis: a review of pertinent radiologic measurements. Spine (Phila Pa 1976). 2005;30(6 Suppl):27-34.

10. Labelle H, Roussouly P, Berthonnaud E, Dimnet J, O'Brien M. Spino-pelvic alignment after surgical correction for developmental spondylolisthesis. Eur Spine J. 2008;17:1170-6.

11. He L, Wang YX, Gong JS, Griffith JF, Zeng XJ, Kwok AW, et al. Prevalence and risk factors of lumbar spondylolisthesis in elderly
Chinese men and women. Eur Radiol. 2014;24: 441-8.

12. Gille $O$, Challier V, Parent $H$, Cavagna R, Poignard A, Faline A, et al. Degenerative lumbar spondylolisthesis. Cohort of 670 patients, and proposal of a new classification. Orthop Traumatol Surg Res. 2014;(6 Suppl)100:311-5.

13. Taillard W. Le Spondylolisthesis Chez L'enfant et L'adolescent1 (Etude de 50 cas). Acta Orthopaedica Scandinavica. 1954;24:115-44.

14. Yang M, Yang C, Ni H, Zhao Y, Li M. The Relationship between T1 Sagittal Angle and Sagittal Balance: A Retrospective Study of 119 Healthy Volunteers. PloS One. 2016;11:e0160957.

15. Wang Z, Wang B, Yin B, Liu W, Yang F, Lv G. The relationship between spinopelvic parameters and clinical symptoms of severe isthmic spondylolisthesis: a prospective study of 64 patients. Eur Spine J. 2014;23:560-8.

16. Baldwin N, Matsunaga S, Ehni B. Spondylolisthesis: sagittal plane lumbar spine deformity correction. Spine Surgery-techniques, Complication Avoidance, and Management. Pennsylvania, PA: Elsevier Churchill Livingstone, Philadelphia 2005;pp:655-74.

17. Mac-Thiong JM, Duong L, Parent S, Hresko MT, Dimar JR, Weidenbaum $M$, et al. Reliability of the Spinal Deformity Study Group classification of lumbosacral spondylolisthesis. Spine (Phila Pa). 2012;37:95-102.

18. Labelle H, Roussouly P, Berthonnaud E, Transfeldt E, O'Brien M, Chopin D, et al. Spondylolisthesis, pelvic incidence, and spinopelvic balance: a correlation study. Spine (Phila Pa 1976). 2004;29:2049-54. 